\title{
Student peer performance evaluation: importance of implementation for group work enhancement
}

\author{
N. Orlova \\ Bohdan Khmelnytsky National University of Cherkasy, Cherkasy, Ukraine \\ Corresponding author. E-mail: orlanvla@ukr.net
}

Paper received 19.09.19; Accepted for publication 07.10.19.

\section{ttps://doi.org/10.31174/SEND-PP2019-207VIII84-05}

\begin{abstract}
In the context of cooperative or group-based learning, student peer performance evaluation can serve a useful instrument because it has a beneficial effect on both the learning process and learning outcomes. It increases students' involvement in the learning process, promotes development of students' autonomy and responsibility. Unfortunately, student peer performance evaluation has not been implemented into the system of higher education in Ukraine. In order to introduce this form of evaluation to Ukrainian universities, it is required to develop tools for students to acquaint them with it, to obtain knowledge of students' views and attitudes towards it and then, train students using the correctly developed instruments. Thus, the aim of the work is to develop tools for collecting information on students' perspectives of peer performance evaluation as a part of the process of teaching-learning English for Specific Purposes. The article has considered the role and place of peer performance evaluation in education, especially its significance in the context of group/team work. The author has generalised and systematised data necessary to design the instruments that can ensure successful implementation of student peer performance evaluation in the process of teaching English for Specific Purposes. As a result, statements for Likert-like Scale Questionnaires have been assumed and formulated to amass data concerning the ways students view the value of the aspects to be evaluated. The questionnaire will cover not only academic factors. It will also include productivity and social and organisational constructs. Moreover, the questions for the semi-structured interview to collect qualitative data have been proposed and formulated. To sum up, it is important to highlight that in case of correctly formulated statements for obtaining peer performance evaluation from the students, members of the same group, and proper implementation of student peer performance evaluation in the educational process in the higher education system in Ukraine, this type of evaluation will be an effective tool that will help improve both the educational process and its outcomes, while fostering the competences required in the further professional life in university students.
\end{abstract}

Keywords: assessment, student peer performance evaluation, cooperative learning, group-based learning, English for Specific Purposes, higher education.

Introduction. Present-day methods and approaches to teaching English for Specific Purposes (hereinafter as ESP) are aimed at the complex development of personalities of university students. They are supposed to be based upon the fundamental principles of student-centred education organisation, students' active involvement in the learning process, development of social interaction skills, taking into account the principles of diversity and inclusion, acquisition of cross-cultural peculiarities, formation of general, special (professional) and integral competences related to students' future professional activities. Today, professional requirements placed on prospective specialists include the high level of profession-oriented knowledge and skills, combination of willingness and ability to master their occupational proficiency, to be a competitive and mobile expert in the modern integrated world. Consequently, the final goal of higher education is to train qualified and competitive specialists capable of meeting employers' demands built upon definite competences of the specific character. [1] Among the methods and approaches used in teaching ESP with varying intensity, cooperative learning is known to promote cognitive activity, increase the level of independence in students in the learning process and so on. [2] The dynamic nature of the educational process within the framework of cooperative learning, awakening of students' natural curiosity, implementation of the approach of active involvement and the use of student-oriented tasks and activities make cooperative learning important for inclusion in the university sy llabus. [3] Despite the lack of its application, cooperative learning is considered a useful approach in teaching ESP because of its deployment of cooperation and collaboration. This approach to ESP learning is focused on the diversity of participants within the learning process and the direct involvement of all students, regardless of their level of knowledge and pace of study. Cooperative learning meets the current requirements for university graduates. Among the latter are the graduates' competencies divided into general, special (professional) and integrated. [4] General competencies include ability to apply the acquired knowledge in practical situations, the readiness and ability for self-development and use of their own potential, ability to solve problems, make informed decisions, the capacity and willingness to analyse and synthesise, interpersonal skills, ability to work in a team. Special or professional competences with in general professional areas include readiness for communication with the purpose of solving problems within future professional activity, possessing the skill of establishing professional contacts and advanced professional communication, the ability to be responsible for the results of one's professional activity personally, etc. Integral competence includes the ability to use in-depth theoretical and fundamental knowledge, to solve complex specific problems during professional activities or the process of study effectively that involves the formation of general and special competencies. [4] While performing educational tasks in the context of cooperative learning, students acquire and develop leadership skills, effective communication skills, establish mutual trust and the ability to resolve conflict situations for the productive group functioning. The implementation of the cooperative approach to ESP teaching and learning will give students the opportunity to take an active part in the learning activities such as idea generation or brainstorming, opinion-exchange, problemsolving, decision-making, puzzle activities, group projects 
or presentations etc, which may include group/team task activities. Therefore, cooperative learning is aimed at forming the majority of the listed competences of graduates. However, cooperative learning, on the one hand, aims to develop certain social and professional competences, on the other hand, it is dependent on personal responsibility and interpersonal skills, as well as systematic discussion and evaluation of group/team work as a whole, and the effectiveness of each individual member. In this case, student peer performance evaluation (hereinafter as SPPE) within the same group is crucial in clarifying the aspects of success or failure, their causes, and finding ways to improve both the learning process and the learning outcomes.

Recent literature and studies review. The analysis of recent studies and publications demonstrated that the issues of implementation of SPPE in higher education institutions in Ukraine had not been addressed. That is why, it was difficult to find and analyse corresponding publications. However, the study is based upon the works of non-Ukrainian authors that have been focused on the usefulness of the application and benefits of SPPE. Thus, recent literature and studies encompass the works of JuiChing Peng from Indiana University who has examined the aspects of peer performance evaluation in terms of teaching foreign languages. The focus of Jerrold Frank has been placed on the concept of assessment and the roles of assessment in language teaching in higher education. Eddy White from Tokyo Woman's Christian University has made successful attempts to study the issues linked to student perspectives of peer assessment for learning within a public speaking course. The work by Irfan Tosuncuoglu has studied importance of assessment and evaluation in teaching the English language. However, there is a relative lack of systematising works on SPPE in the tertiary educational level in Ukraine. Thus, it would be essential to make attempts to research this subject, systematise the data collected and develop the tools required to detect university students' views on peer performance evaluation in order to implement this type of formative assessment into higher education settings in Ukraine.

The article aims to substantiate the necessity of creating an effective tool for implementing and conducting SPPE in the system of higher education in Ukraine. Thus, the work was aimed to develop instruments for collecting qualitative and quantitative understanding of the students' views on peer performance evaluation in the context of ESP teaching at the tertiary educational level in Ukraine. To collect quantitative data, Likert-like Scale Questionnaires should be designed and developed. For qualitative data collection, it is necessary to design and develop semi-structured interviews for later thematic breakdown to investigate the backgrounds leading to the ways students consider and perceive peer performance evaluation in the ESP context.

Materials and Methods. To achieve the objective, the following methods of analysing scientific and methodological literature on the topic under research; designing and development of the pedagogically approved interview questions and Likert-like Scale Questionnaires for their subsequent implementation; theoretical generalisation, and systematisation have been applied.
Results and Discussion. SPPE in the context of cooperative learning can be a useful tool that will improve both the learning process and its outcomes, but it also prepares students for engaging in and accomplishing group tasks in their future professional fields as successful and productive industry professionals who work together to achieve common goals. Cooperative or group-based learning is highly dependable on various sociopsychological factors. The most influential group-work phenomena include social facilitation and social loafing. The latter is an example of social inhibition as a general effect where the presence of others interferes with or inhibits the carrying out of actions [5]. According to Colman (2009), social loafing as a tendency to reduce the effort toward a task as part of a cooperative group, tends to occur when individuals contribute to a group product. [6] In academic, cooperative settings, the effect of social loafing can be noticeable as students put less effort into solving academic or applied cognitively complex problems when these tasks are carried out in a group. As been mentioned by Zajonc (1965), a reason for social loafing to occur can be the presence of other people that can make individuals feel relaxed and anonymous. [7] Another cause of group pathologies including social loafing described in a recent comprehensive review on group behaviour by Baumeister et al (2015) linked their occurrence to submerging of the individual self in the group. [8] Thus, social loafing can be reduced by making individual contributions identifiable within the group evaluated adequately. It means that group members' efforts can be enhanced when the group is subject to student peer performance evaluation. SPPE can improve reciprocal communication within the group; consequently, better communication quality will promote the reduction of social loafing.

As stated by Hall (2011), assessment as the general process of monitoring or keeping track of the learners' progress can fulfil both a formative and summative role. [9] Jerrold Frank suggested that student peer evaluation can serve an effective alternative form of formative assessment involving students who themselves evaluate each other's levels of participation, engagement, behavioural and organisational a spects. [10]

In higher education in Ukraine, summative assessment focusing on results of learning, in other words, on learning as an end product, is traditionally used to grade students who are exceptionally passive in the process of assessment. Formative assessment, or evaluation aims to facilitate the development of content and competences through evaluation of students' own activity and that of their peers', members of the same group, activity. In this case, students play an active role and are highly involved in the teaching-learning process as its valuable part. However, this form of evaluation is not widespread in the system of higher education in Ukraine. It is significant to promote and implement SPPE in the tertiary educational level in Ukraine, as it is supposed to be beneficial for both learning as a process of gaining new knowledge, skills and competences, and learning outcomes as a final product to be assessed summatively by a tutor. Due to its features, SPPE helps students develop essential skills, increases students' autonomy and engagement as well as enhances the degree of responsibility towards their own 
learning and that of other students. SPPE is usually associated with group/team work with each group/team member's contribution to the process and final product being significant. The levels of group/team work competences and skills can hardly be assessed by teachers or tutors solely. As a rule, group members have more opportunities to amass the information required for a sufficient evaluation. Thus, SPPE can be considered an effective tool for tutors aiding them in a group-work evaluation. However, it is crucial to point out the weaknesses SPPE has. Information about students obtained from students, peer group members, is definitely influenced by social acceptance within a group, students' relationships and attitudes towards other group members. Depending on relationships within a group, or personality traits of individual students, group members can either express unwillingness to criticise other students as their friends or be overwhelmed by a wish to overcriticise those they have bad relations with or negative attitudes to. As the subjectivity seems to be the main weakness influencing the effectiveness of SPPE, the thorough evaluating instruments should be developed to solve the issue. The students need explanation, demonstration, preparation and training. As stated by HainsWesson (2013), the teaching staff should inform students and discuss aspects linked to SPPE, starting with its objectives, procedure and expecta tions. [11]

Since SPPE is not incorporated into the system of higher education in Ukraine, its implementation in the context of teaching ESP requires substantial preparation, including preliminary studies on students' perspectives on possibilities of involvement into SPPE, design and development of questionnaires, experiment verification of the influence SPPE has on the progress of individual students as well as of team/group work, and subsequent implementation of SPPE into the learning progress. Thus, effective SPPE implementation requires development of SPPE tasks with clear, unambiguous, and understandable criteria and standards, engagement in training and practicing SPPE activities before actual employment of SPPE. In case of evaluating students' contribution to group work or project, it should be clearly stated what degree, content and extent of a student's contribution will be evaluated. Therefore, it is vital for students' explicit encouragement to provide them with adequate instruments to practice SPPE effectively. In this context, it is necessary to know students' views of the form and contents of SPPE questionnaires, as well as their attitudes towards SPPE as a prospect form of evaluation during ESP teaching and learning.

Since the purpose of this work is to design SPPE tools, including interview questions and Likert-like scale questionnaires for obtaining information concerning tertiary students' perspectives on SPPE and its implementation in the process of ESP teaching and learning. To develop effective SPPE instruments to examine students' views on SPPE for learning and improvement of the learning process and learning outcomes with regard to group/team work, we need to distinguish students' key skills and activities to be evaluated by their peers. As mentioned by Peng (2010), the core skills revealed during students' group work to be evaluated encompass participation in group meetings and discussions, degree of preparation for meetings and discussions, communication with other group members, effective contribution to group work and fulfilment of allocated responsibilities. [12] It is assumed that these five skills are definitely associated with group/team work and should be included into questionnaires. However, some skills are more complicated. Consequently, they need formulation that is more detailed. To amass required data concerning students' personal attitudes and considerations as for SPPE and its implementation, it is essential to design a questionnaire for conducting a semi-structured interview. Moreover, a Likert-like questionnaire should be created to collect information about students' thoughts and views on the aspects to be covered through SPPE while and after carrying out group/team work. Since collaborative group/team work presupposes that not only academic factors will be involved, it is necessary to add evaluating statements concerning social aspects, productivity and organisational constructs.

Consequently, the questions for a semi-structured interview are supposed to clear up the following:

Have you ever experienced SPPE?

Do you think your personal relationships can influence the objectivity of your evaluation?

How will your personal relationships influence your evaluation of other group members?

Can SPPE influence the quality of the whole group/teamwork? (If Yes - explain how)

Can SPPE influence productivity of work of individual group members? (If Yes - explain how)

Can SPPE be used as a means to influence group members?

Is there a possibility that the prospective implementation of SPPE will improve the quality of preparation and learning outcomes of group/team work?

Will SPPE implementation influence group/team work dynamics? (If Yes - explain how)

Do you consider it necessary to implement SPPE in the system of higher education in Ukraine?

The Likert-like scale questionnaire statements can be divided into four skill groups: an academic field, an organisational side, productivity and social factors. The academic aspects to be evaluated cover awareness and ease with material under discussion, enthusiasm and interest in the project contents, intellectual contributions made to the group/team project discussion etc. The organisational side will be represented by the following statements: regular and punctual attendance of group meetings, prompt completion of the assigned tasks, qualitative preparation of the tasks assigned, accuracy in task completion, participation in developing ideas and planning project work, participation in leading or facilitating group/team work or discussion, reliability in terms of attending group/team work meetings. Students' effectiveness and productivity may be evaluated through the next assertions: the amount of work done, the quantitative value of the useful ideas brought in, willingness and readiness to accept and fulfil the tasks given, accurate and complete completion of the assigned tasks. Among social skills, we should dist ingu ish demonstration of cooperation and support with other members of the group, willingness to cooperate with individual members of the group in successive project work, the degree of contribution of each group member to the collective project work, will- 
ingness to discuss the ideas of others, assistance and readiness to foster and support other group members, capacity to share thoughts, listen attentively and appreciate the views of other group members, positive contribution to the group work, assistance and support given to other members of the group in their tasks, awareness of the personal value of each group member.

Conclusions. SPPE is believed to be very useful in order to prevent social loafing, since it can help distinguish individual contribution from group products. [12]. However, to become actively engaged in SPPE, students should be aware of its benefits, know how to learn from it, not just simply judge others and be judged by others. The non-directive nature of SPPE promotes its positive association with forthcoming improvements and developments in students' current learning process as well as their future career. In order to implement SPPE effectively, we should consider students as signif icant stakeholders with their individual and different from those of teaching staff perspectives on SPPE in general and within ESP context in university settings. Subsequently, the implementation of SPPE will serve a functional construct of the process of teaching students at the tertiary educational level in Ukraine.

\section{REFERENCES}

1. Orlova, N. (2018). English Language Teaching at the Tertiary Education Level: Syllabus Types and Design. // Cherkasy University Bulletin, Pedagogical Sciences Series. Issue №1, 2018 - Cherkasy, 2018. - 150 p. (pp. 81-87 )

2. Orlova, N. (2019). Teaching Foreign Languages for Occupational Purposes to University Students of Non-linguistic Study Fields: Concept's Multifaceted and Complex Nature.// Humanities Science Current Issues: Interuniversity collection of Drohobych Ivan Franko State Pedagogical University Young Scientists Research Papers. - Drohobych: Publishing House "Helvetica", 2019. - Issue 23. Vol. 3, 2019. - 188 p. (93-99 pp.) DOI: http://doi.org/10.24919/23084863.3/23.166379

3. Orlova, N. (2016). Methods of Increasing Motivation for Learning Foreign Languages for Occupational Purposes. // Cherkasy University Bulletin, Pedagogical Sciences Series. Issue № 3, 2016 - Cherkasy, 2016. - pp. 89-95

4. Orlova, N. (2017). Competence-B ased Education: Context Analysis for the Subject Area of Philology. // Abstracts of papers'17: Philological Education in Modern University Project-based Approach to the Work Organisation According to the Guidelines of the European Qualifications Framework (Experience of Danubius University) (pp. 71-76). Sladkovicovo.

5. Reber, A. S., Allen, Rh.,\& Reber, E. S. (Ed.). (2009). The Penguin Dictionary of Psychology $\left(4^{\text {th }} \mathrm{Ed}\right)$. London: Penguin Books.

6. Colman, A. M. (Ed.). (2009). A Dictionary of Psychology (3d Ed.). Oxford and New York: Oxford University Press.

7. Zajonc, R. B. (1965). Social Facilitation. // Science, New Series, Vol. 149, №3681. Jul. 16, 1965, pp. 269-274.

8. Baumeister, R., Ainsworth, S. \& Vohs, K. (2015). Are Groups More or Less than the Sum of their Members? The Moderating Role of Individual Identification. // The Behavioral and brain sciences. 2015, May 1. pp.1-38 DOI: 10.1017/S0140525X15000618.

9. Hall, G. (2011). Exploring English Language Teaching: Language in Action. New York: Routledge.

10. Frank, Jerrold. (2012). The Roles of Assessment in Language Teaching. English Teaching Forum, Vol. 50, № 3, C. 32, retrieved 10.09.2019 from https://files.eric.ed.gov/fulltext/EJ997527.pdf.

11. Hains-Wesson, R. (2013). Peer and Self Assessment. Retrieved 10.09.2019 from https://www.deakin.edu.au/_data/assets/pdf_file/0020/53462 /peer-and-self-assessment.pdf.

12. Peng, Jui-ching. (2010). Peer Assessment in an EFL Context: Attitudes and Correlations. // Selected Proceedings of the 2008 Second Language Research Forum, ed. Mathew T. Prior et al., 89-107. Somerville, MA: Cascadilla Proceedings Project. 